\title{
RELAÇÕES TEÓRICO-CONCEITUAIS ENTRE IDENTIDADE E MEMÓRIA NA PERSPECTIVA DA CIÊNCIA DA INFORMAÇÃO
}

\author{
THEORETICAL-CONCEPTUAL RELATIONS BETWEEN IDENTITY AND \\ MEMORY IN THE PERSPECTIVE OF INFORMATION SCIENCE
}

\author{
Edilson Targino Melo Filho
}

UFJR/IBICT

\begin{abstract}
RESUMO
Trata das relações práticas entre os conceitos memória e identidade a partir da perspectiva da Ciência da Informação. Utiliza-se de conceitos de identidade e memória para relacionar o processo de construção da identidade na perspectiva da Ciência da Informação. Os conceitos são levados para a Ciência da Informação a fim de perceber a importância da discussão dessas temáticas, colocando os profissionais da informação como sujeitos sociais capazes de discutir e entender esse processo, sobretudo por perceber a representação da identidade inserida na sociedade da informação. ${ }^{1}$
\end{abstract}

Palavras-chave: Memória. Identidade. Ciência da Informação.

\section{ABSTRACT}

The present paper is about the practical relations between the concepts of memory and identity, from the perspective of Information Science. It uses concepts of identity and memory to relate the process of identity construction in the perspective of Information Science. The concepts are taken to Information Science in order to perceive the importance of discussing these themes, putting information professionals as social subjects that are able to discuss and understand this process, especially by perceiving the representation of identity inserted in information society.

Keywords: Memory. Identity. Information Science.

\footnotetext{
${ }^{1}$ Artigo fruto de discussões realizadas na disciplina Memória, Organização, Acesso e Uso da Informação, no Programa de Pós-Graduação em Ciência da Informação da Universidade Federal da Paraíba.
} 


\section{INTRODUÇÃO}

Tendo em vista as limitações da memória humana, sobretudo no que concerne à capacidade de armazenamento e recuperação das reminiscências, o homem procurou outras formas de armazenar "conhecimento", e o resultado dessa incessante busca foi denominado de 'memórias artificiais' (OLIVEIRA; RODRIGUES, 2011). Essa procura levou à criação de instituições de memórias: arquivos, bibliotecas e museus, o que, consequentemente, com o desenvolvimento e sistematização das técnicas por elas aplicadas, originaram novas áreas de saber: Arquivologia, Biblioteconomia e Museologia.

Nesse aspecto, é necessário entender a criação das instituições de memórias como parte integrante da concepção de preservação da identidade cultural e social. Ao falar de memória, entende-se como um trabalho de construção de identidades.

Com o surgimento da Ciência da Informação (CI), pós-Segunda Guerra Mundial (SARACEVIC, 1996), esta tem como tarefa estudar e propor soluções para os problemas relacionados à transferência da informação. Neste sentido, o contexto em que se encontra a sociedade parece reforçar a ideia de tornar mais explícitas as concepções de memória que permeiam o conhecimento produzido pela CI.

A memória, por muito tempo, foi considerada algo divino, que elevava os mortais ao mundo das divindades, e com o passar dos tempos ela passa por um processo de laicização, desempenhando um importante papel no desenvolvimento das ideias. Neste sentido, a memória é entendida como "a capacidade humana de reter fatos e experiências do passado e retransmiti-los às novas gerações [...] graças a um conjunto de funções psíquicas." (OLIVEIRA; RODRIGUES, 2008, p. 3). Ou seja, a memória perpassa os processos cognitivos porque, em alguns casos, é instituída de maneira inconsciente.

Neste aspecto, Bergson (1999) distingue dois tipos de memória: a memória hábito e a memória pura. A memória hábito é adquirida de maneira automática e passa pelo ato de repetição; e a memória pura é aquela que independe da consciência, pois se refere ao ato de recordar coisas do passado. Esta é a visão psicológica da memória de Bergson (1999) e se refere ao aspecto individual, mas a memória ainda pode ser entendida como fenômeno social, como uma construção social.

Somente a partir do século XX é que o mundo começa a ser visto como um espaço informacional e memorial, em que os aspectos materiais e imateriais dos objetos criados pelas sociedades entram na disputa pelo desenvolvimento do conhecimento. Ademais, conforme assevera Dodebei (2010), Informação, Memória e Conhecimento são a face 
imaterial da economia representada pelo consumo de bens que transitam nas redes sociais ubíquas e, concomitantemente, a face material dos percursos da valorização de bens culturais e da preservação de patrimônios.

Destarte, a busca pela valorização profissional e a preocupação com os estoques informacionais crescentes, sobretudo por volta de 1960, despertaram a reinserção social das experiências dos mais antigos no desenvolvimento de técnicas que proporcionassem a construção da identidade de um grupo. Neste sentido, a história oral tem sua contribuição, como destaca Pollak (1992, p. 207), “a coleta de representações por meio da história oral tornou-se claramente um instrumento privilegiado para abrir novos campos de pesquisa", essa coleta é representada pelas fontes de informações das quais emana, além das experiências vividas, suas identidades construídas ao longo do tempo.

É fácil então perceber que, conforme afirmam Pieruccini e Perrotti (2010, p. 6), “a história de vida de cada indivíduo faz parte, assim, de uma história mais geral", que ora está associada ao coletivo, ora está dissociada, entretanto é arquitetada no "complexo e permanente fluxo de relações entre as memórias que forja o todo social, a ancoragem para a construção contínua e comum da experiência matéria”, pessoal e coletiva.

Neste sentido, este estudo tem como objetivo relacionar os conceitos de identidade e memória propostos por Henri Bergson (1999), Maruricie Halbwachs (2006), Paul Ricouer (2007) e Jöel Candau (2011) com a CI, a fim de abordar a interseção destes conceitos com os aspectos da mediação do profissional da informação.

0 estudo trata-se de um artigo de revisão, exclusivamente teórico. Os autores selecionados para a interlocução surgem de discussões no âmbito da disciplina Memória, Organização, Acesso e Uso da Informação. Entende-se essa relação a partir do processo de mediação proposto pelo profissional da informação no que concerne às aplicações práticas do campo teórico desses conceitos.

\section{MEMÓRIA: um estado de consciência}

Ao tratar de memória e, consequentemente, do estado de consciência, certamente Bergson (1999) entrará na discussão proposta, tendo em vista que em seu escrito mais consagrado, "Matéria e Memória: ensaio sobre a relação do corpo com o espírito", de 1986, ele trata da relação do corpo com o espírito, da matéria com a alma, do realismo e do idealismo. 
Evidentemente, Bergson (1999) prepara sua obra para o entendimento de uma percepção consciente, que atua como relógio da indeterminação da ação, e está voltada para o momento em que há uma possibilidade de hesitação e, consequentemente, de escolha, isto é, de indeterminações das ações. É neste momento em que há uma percepção consciente.

É neste entendimento que, buscando a ideia de percepção consciente, Bergson (1999) alerta para uma crítica ao realismo e ao idealismo, na medida em que ambos apresentam dificuldades em suas teses no processo de determinação da relação entre matéria e espírito. Para dirimir as subjeções tanto do realismo quanto do idealismo, Bergson (1999) passa pela caracterização das imagens, ele entende estas como "uma certa existência que é mais do aquilo que o idealista chama uma representação, porém menos do que aquilo que o realista chama coisa." (BERGSON, 1999, p. 2). Então, a imagem está localizada no entremeio da representação e da coisa, é uma realidade exterior ao indivíduo que observa, mas é também compartilhada por ele, transportada por ele de alguma maneira.

É possível, então, perceber que o conceito de memória perpassa o reconhecimento das imagens, de maneira que está relacionada como um campo transcendental pré-subjetivo, conforme versa o próprio Bergson (1999). Ao abordar as questões conceituais de memória, podemos ter como base não só esse campo transcendental inerente ao sujeito, mas a sua percepção consciente em relação às imagens postas, e porque não dizer em relação ao contexto informacional que ora se apresenta.

Conforme discorre Orrico (2010, p. 5):

[...] a inserção do conceito de memória decorre da compreensão de que a formação do imaginário da população, e ainda da construção da identidade de um grupo social, acontece pelo que a linguagem constrói discursivamente, estabelecendo os processos de transmissão cultural, construindo o que o grupo lembra individual e socialmente.

Dado esse estado de consciência que é intrínseco ao contexto informacional, mas também extrínseco aos processos de transmissão cultural, a construção da memória e a representação que faz parte da sua concepção demandam a passagem da imagem para a sua representação. Essa conversão é necessária para o entendimento da concepção de memória enquanto estado consciente. 
A partir desse entendimento, compreendemos a memória como um estado de consciência que não é de todo individual, mas também é construído coletivamente, e assim por diante, contribuindo essencialmente na construção da identidade, tendo em vista o resgate das lembranças coletivas que são evocadas pelos outros e não nos são estranhas, mas sim familiares.

Nesse sentido, Halbwachs (2006) aborda essa questão da memória enquanto fenômeno coletivo, que se apropria das condições socialmente construídas para o seu estabelecimento, além de se instituir por meio de indivíduos que não necessariamente devem estar presentes materialmente para que a evocação ocorra em sua plenitude, mas compreendendo o campo transcendental.

\footnotetext{
Nossas lembranças permanecem coletivas e nos são lembradas por outros, ainda que se trate de eventos em que somente nós estivemos envolvidos e objetos que somente nós vimos. [...] Não é preciso que outros estejam presentes, materialmente distintos de nós, porque sempre levamos conosco e em nós certa quantidade de pessoas que não se confundem. (HALBWACHS, 2006, p. 30).
}

Então, na concepção de Halbwachs (2006), as lembranças não se perdem no espaço, mas são evocadas constantemente, mesmo porque delas decorre a construção da identidade social dos indivíduos. Neste sentido, "no momento em que examina seu passado, o grupo nota que continua o mesmo e toma consciência de sua identidade através do tempo." (HALBWACHS, 2006, p. 108).

0 autor continua enfatizando que "é difícil conceber como despertaria em uma consciência isolada o sentimento da identidade pessoal, talvez porque nos parece que um homem inteiramente só não poderia se lembrar de modo algum." (HALBWACHS, 2006, p. 110). Portanto, é válido ressaltar que a construção da identidade perpassa pelo estado de consciência, assumindo características próprias, mas carregando traços do coletivo.

O que certamente não poderá entrar em colapso são as concepções de memória histórica e memória coletiva, tendo em vista que memória histórica é entendida pela sequência de eventos, cuja lembrança a história conserva; portanto, a memória coletiva não pode ser confundida com a história. Entretanto, conforme ressalta Nora (1993, p. 28) "a memória, com efeito, só conheceu duas formas de legitimidade: histórica ou literária", é com este entendimento que surge o confronto, ou melhor, a associação da memória com a identidade, entendendo ainda a importância e o destaque feito por Nora 
(1993) aos lugares de memória que consolidam as memórias e que, necessariamente, precisam de uma vontade de memória para se efetivar como tal.

A memória de grupo está em consonância com as lembranças das experiências dos membros. Baseado na percepção da imagem de Bergson (1999) é possível reencontrar as ligações do pretérito. Evidentemente, Halbwachs (2006) chama a atenção para a intuição sensível que está sempre no presente, entendendo que a memória pode ser evocada em função do pensamento coletivo.

Neste sentido, o sujeito participa de dois tipos de memórias: individuais e coletivas. Apesar de a memória coletiva conter a memória individual, elas não se confundem.

Halbwachs (2006) ressalta as divisões do tempo que resultam de convenções e costumes. É importante salientar este ponto tendo em vista que a memória não tem poder sobre os estados passados e que o tempo social não se confunde mais do que a duração individual com o tempo matemático. Então, não há grupo que não sinta necessidade de distinguir e identificar as diversas partes de sua duração, visto que o tempo só é real na medida em que materializa acontecimentos. No que concerne ao espaço como campo da memória, o ambiente é marcado por traços dos indivíduos que modelam o espaço à sua imagem; contudo se adaptam às coisas materiais que a ele resistem. Neste sentido, ele afirma que não há memória coletiva que não aconteça em um contexto espacial.

Há, ainda, um aprofundamento sobre a memória dos músicos. $\mathrm{O}$ autor afirma que ela é mais extensa e bem mais segura que a dos outros, isto porque o cérebro está habituado com os sons musicais que se fixaram na memória. Logo, as lembranças dos músicos se conservam em uma memória coletiva que se estende no espaço e no tempo, tão longe quanto sua comunidade.

Então, a memória não poderia estar desfalcada dos conceitos de percepção, espaço e tempo, principalmente porque estes se relacionam. Ademais, a memória coletiva é partícipe da memória individual, que se configura como importante fator determinante da identidade dos sujeitos e, portanto, entendendo a memória como um estado de consciência, visto que as lembranças são permanentemente evocadas em um conjunto de representações que formam a identidade. 


\section{IDENTIDADE: CONJUNTO DE REPRESENTAÇÕES COLETIVAS}

Inicialmente, é necessário ressaltar que "há uma ligação fenomenológica muito estreita entre memória e o sentimento de identidade." (POLLAK, 1992, p. 204). A partir de então, podemos perceber a memória como elemento essencial na construção da identidade social. Segundo Pollak (1992, p. 204):

[...] a memória é um elemento constituinte do sentimento de identidade, tanto individual como coletiva, na medida em que ela também é um fator extremamente importante do sentimento de continuidade e coerência de uma pessoa ou de um grupo em sua reconstrução de si.

Neste aspecto, Candau (2011) também vai tratar a identidade como intimamente ligada à memória, tendo em vista seu processo de construção social.

No seu livro intitulado "Memória e Identidade", Joël Candau (2011) procura estabelecer as relações entre memórias individuais e coletivas, entendendo a identidade como um estado psíquico e social e a memória como uma faculdade individual e um conjunto de representações. Além disso, ele ainda analisa o conceito de memória a partir de três níveis: protomemória, memória de evocação e metamemória, diferenciando as memórias fortes e fracas.

A protomemória poderia, em algum momento, ser confundida com o habitus de Bourdieu (2009). Candau (2011) afirma que o habitus depende da protomemória. Contudo, a protomemória é o próprio senso prático, segundo o qual o passado não chega sequer a ser representado, porque já agiria no corpo. Ela é a memória social incorporada. Neste sentido, Candau (2011, p. 23) conceitua a protomemória como "uma memória 'imperceptível', que ocorre sem tomada de consciência. Ela é essa forma de memória que trabalha o corpo sem relaxar, esculpindo-o para fazer dele um corpo mimesis e que é a alienação fundadora da identidade."

A memória de evocação é a memória propriamente dita. É uma recordação ou evocação voluntária. Como bem ressalta Candau (2011), é feita igualmente de esquecimento e pode se beneficiar de extensões artificiais que derivam do fenômeno geral da expansão da memória.

A metamemória é a representação que cada indivíduo faz de sua própria memória e se constitui na forma de memória reivindicada, ostensiva. Consequentemente, contribui para a construção identitária. Por conseguinte, a 
metamemória é a representação que fazemos das próprias lembranças, o conhecimento que temos delas. Então, a metamemória é "a representação que cada indivíduo faz de sua própria memória", é a construção explícita da identidade, "a metamemória é, portanto, uma memória reivindicada, ostensiva." (CANDAU, 2011, p. 23).

A memória forte é aquela estruturante de identidade, capaz de organizar sentido. Segundo Candau (2011, p. 44), ela é "uma memória massiva, coerente, compacta e profunda", imposta a uma grande maioria dos membros de um grupo, independente do seu tamanho; contudo, salientando que a possibilidade de encontrar tal memória é bem maior quando o grupo é pequeno.

A memória fraca não possui traços bem definidos. Candau (2011) a define como difusa e superficial, ela é dificilmente compartilhada por um conjunto de indivíduos. Esse fato corrobora para que a identidade coletiva do grupo seja relativamente inatingível. Segundo o próprio Candau (2011), uma memória fraca pode contribuir para a desestruturação de um grupo.

Em síntese, a memória forte seria estruturante de identidade, capaz de organizar sentido, o que o autor vai denominar de retórica holística. No caso da memória fraca, ela tem a sua origem gradativa na transformação dos grupos, conforme seus quadros sociais de memória.

No que se refere à identidade, Candau (2011) afirma que o termo se refere a um estado, e que ele não poderia ser aplicado nem ao indivíduo muito menos a um corpo social, pelo menos em tese. De acordo com o autor, os estados mentais são incomunicáveis, e nada pode ser observado pelos sujeitos simultaneamente. Neste sentido, as identidades estão ancoradas em torno da origem e do acontecimento, o que Candau (2011) vai denominar de pedras numerárias. Então, há um reconhecimento por parte de Candau (2011) na origem e no acontecimento em que se tornam perceptíveis dois alicerces temporais importantes, segundo os quais os processos identitários são possíveis.

Neste sentido, é preciso ressaltar a preocupação com os processos de socialização da memória, que pode ser "objetiva quando se trata de uma memória factual e que é, pelo menos, o sentimento subjetivo que os membros de um grupo possuem de compartilhar a mesma memória." (CANDAU, 2011, p. 45). Desse modo, o importante é assegurar que os processos identitários estão balizados na memória, perpassando os três níveis distinguidos, mas, sobretudo, pela memória de evocação. 
É necessário analisar a relação da memória com as demais categorias que lhe são costumeiramente associadas: imagens, representação, esquecimento, entre outras. Então, o esquecimento e o perdão como parte integrante da memória, e esta como a grande mola propulsora para as relações narrativas surgidas no instante em que se faz memória.

Destarte, conforme destaca Candau (2011, p. 50), "a memória coletiva, como a identidade da qual ela é o combustível, não existe se não diferentemente, em uma relação sempre mutável mantida com o outro." Desta forma, a construção da identidade intercepta a memória coletiva, tendo em vista que, para a construção identitária, seja dos indivíduos, seja das coletividades, é necessário um resgate histórico da memória.

Neste processo, encontra-se a CI, que busca delinear seus conceitos de memória, definindo os aspectos sociais e cognitivos que abarcam as percepções acerca do tema e, assim, deliberando as feições que o conceito de memória trará para a CI como um todo e para os profissionais da informação.

\subsection{A IDENTIDADE DESMEMORIADA}

Diante dos aspectos dispostos da percepção da memória e da construção identitária a partir da evocação das lembranças, e todas as suas nuances, podemos, então, estabelecer uma hipótese de que não há identidade sem que nesta estejam impregnados traços da memória, seja individual ou coletiva. Neste sentido, Riccoeur (2007, p. 469) reforça que "as representações fragmentárias da memória seguem as linhas de dispersão da lembrança. A reflexão, em compensação, remete ao foco da memória do si que é o lugar da afecção constitutiva do sentimento de falta."

Ao engendrar esforços para conceber essa identidade que não está dissociada da memória, mas estão intrinsecamente ligadas, a identidade e a memória convergem para a ideia de um sujeito social, consciente da sua trajetória de vida, da sua história que certamente produz nele um aspecto consciente.

Entretanto, o próprio Candau (2011, p. 18) chama a atenção para a capacidade da memória em derrocar o anseio pela identidade: "a memória é a identidade em ação, mas ela pode, ao contrário, ameaçar, perturbar e mesmo arruinar o sentimento de identidade." Isso pode ser evidenciado ao fazer uma anamnese de abusos sexuais ou fazer uma memória do Holocausto. Candau (2011, p. 18) reforça ainda que "o jogo da 
memória que vem fundar a identidade é necessariamente feito de lembranças e esquecimentos.” Então, é nessa dualidade entre lembrar e esquecer que a identidade é construída e percebida pelos sujeitos.

Portanto, é constatado em Pinheiro Filho (2004) que a realidade humana é fato social e, por isso, é construída na coletividade, na integração com outro. A representação da identidade que está inserida na sociedade, e por meio dela se materializa no ser humano, é capaz de produzir no homem, a partir da tradição filosófica, a sua ressignificação com o meio:

O indivíduo não é ainda realidade humana, mas apenas abstração que só se perfaz no meio social. Antes de sua constituição na e pela força coletiva, não se pode falar propriamente de homem, mas de um ser que se reduz ao organismo animal. A humanidade do homem é coisa social, que se cristaliza por mecanismos de coerção. (PINHEIRO FILHO, 2004, p. 142, grifo do autor).

Conforme destaca Pollak (1992, p. 204), “a construção da identidade é um fenômeno que se reproduz em referência aos outros, em referência aos critérios de aceitabilidade, de admissibilidade, de credibilidade, e que se faz por meio da negociação direta com os outros.” Desta forma, esse fenômeno decorrente da referência só é possível por causa dos aspectos memoriais presentes em cada aspecto.

É, portanto, necessário destacar a forma pela qual a identidade não está dissociada da memória e, por conseguinte, da informação que a ela é atribuída enquanto fenômeno social. De acordo com Pollak (1989, p. 13), "tanto no nível individual como no nível do grupo, tudo se passa como se coerência e continuidade fossem comumente admitidas como os sinais distintivos de uma memória crível e de um sentido de identidade assegurados."

Então, é possível assegurar as nuances que corroboram para uma continuidade na construção da identidade, já que ela não é estática, é mutável e está em constante construção, tendo em vista que os seres humanos são seres sociais que também estão em constante interação, o que certamente produz, a todo instante, fenômenos sociais, dependentes dos sujeitos.

A identidade e a memória caminham juntas, embora seja necessária a produção e reprodução de saberes inerentes à identidade e à memória, isto porque o grupo em que os sujeitos estão inseridos também se envolve na manutenção da identidade profissional, conforme destaca Candau (2011, p. 118): "todo grupo profissional valoriza os comportamentos apropriados e reprime os demais a fim de produzir uma memória 
adequada à reprodução de saberes e fazeres e à manutenção de uma identidade da profissão." Desta forma, é dada a devida importância ao grupo profissional, cultural, social que o indivíduo se insere, tendo em vista que o individual é construído pela coletividade.

Portanto, o sujeito vive uma incessante busca pela sua formação identitária, mesmo que essa busca seja feita de maneira inconsciente, mas há a necessidade de evocar memórias para que esse processo se desenvolva, como afirma Halbwachs (2006, p. 108): "no momento em que examina seu passado, o grupo nota que continua o mesmo e toma consciência de sua identidade através do tempo." Perpassando os aspectos imateriais da memória, o grupo tem por escopo eternizar os sentimentos e as imagens que formam a essência do seu pensamento e, consequentemente, formam a sua identidade.

Ao contrário do que se imagina, não é fácil conceber um sujeito que despertaria sua identidade pessoal de maneira isolada, sem a ajuda do grupo social em que está inserido. É como deixa claro Halbwachs (2006, p. 110) quando afirma que "é difícil conceber como despertaria em uma consciência isolada o sentimento da identidade pessoal, talvez porque nos parece que um homem inteiramente só não poderia se lembrar de modo algum.” É a integração com seus pares que permite não somente a evocação da memória, mas a construção identitária.

Da mesma forma, Candau (2011) procurou reconhecer nos acontecimentos e na origem os principais fundamentos temporais segundo os quais os processos identitários são possíveis. Por conseguinte, em meio aos processos de socialização da memória, onde a personalidade de cada ser humano é marcada pelos traços do convívio com o outro, é necessário compreender como "as ideologias que prevalecem nas memórias migrantes jogam com as fronteiras da alteridade para produzir, pela distinção, as identidades sociais." (CANDAU, 2011, p. 17), entendendo as ideologias como um processo natural e coercitivo que é inerente ao ser humano, pois independe da sua vontade de fazer ou agir com memória.

É a capacidade produtora da memória que produz identidade e que promove as relações sociais inerentes a esse processo, conforme afirma Candau (2011, p. 78): 
no tecido das imagens e da linguagem que devemos à sociedade e que nos vai permitir dar uma ordem ao mundo.

Neste sentido, Candau (2011) corrobora com Bergson (1999) quando este elabora a concepção do jogo de imagens como fonte de onde emana a memória, e quanto trata da percepção consciente no quadro de amparo às memórias. Então, significa que "perceber consiste, portanto, em suma, em condensar períodos enormes de uma existência infinitamente diluída em alguns momentos mais diferenciados de uma vida mais intensa, e em resumir, assim, uma história muito longa. Perceber significa imobilizar." (BERGSON, 1999, p. 244). Nesta perspectiva, tratando o tempo como um importante aspecto no processo identitário.

Segundo destaca Ricouer (2007, p. 96), “é mesmo enquanto fator de integração que a ideologia pode ser tida como guardiã da identidade, na medida em que ela oferece uma réplica simbólica às causas de fragilidade dessa identidade", pois é essa ideologia que armazena a memória e dela só poderá ser obtida a partir das evocações que os indivíduos lançarem mão.

\section{CONSIDERAÇõES}

Nestas condições, a incessante busca pela identidade desmemoriada não se trata apenas do ávido esforço de memória para perceber a identidade, mas da investigação necessária para compreender os processos inerentes a essa percepção. É, portanto, significativo o ânimo engendrado pelos fenômenos sociais que funcionam, também, como mola propulsora no desenvolvimento identitário.

É da sociedade que emana todas as fontes de significação, seja na construção da identidade, seja na evocação da memória para tal. Segundo Pinheiro Filho (2004, p. 142), “a sociedade é a única fonte da humanidade do homem; é através dela que se transcende a pura vida orgânica que é a condição do homem tomado em sua individualidade." Neste sentido, podemos perceber que a individualidade é construída na coletividade, e, consequentemente, o processo identitário surge, também, dessa força da coletividade que abriga o desejo de ser notado enquanto sujeito social.

Conforme destacado por Candau (2011), a memória coletiva é a chama necessária para a construção da identidade, sempre partindo da dinâmica da relação com o outro. Por conseguinte, a noção de representação também intercepta a construção da 
identidade, tendo em vista que "toda representação é produto de uma síntese" (PINHEIRO FILHO, 2004, p. 144), e a identidade é o conjunto de representações do indivíduo, marcado pelas referências dadas nos acontecimentos da trajetória do sujeito.

Destarte, é importante ressaltar a necessidade de organização das representações identitárias, pois cada uma delas precisa, além de resgate memorialístico, de um eixo temporal no qual estejam ancoradas nas representações coletivas. Neste aspecto, reforça Candau (2011, p. 91): “o tempo, assim provisoriamente domesticado nesse templo da memória coletiva, autoriza a ancoragem de cada sujeito em uma temporalidade fundadora da identidade." Então, a questão da construção da identidade não está alicerçada somente na memória, mas em todo o contexto que envolve os aspectos de construção social da realidade que, certamente, decorre do movimento dialético da memória: esquecer e lembrar.

A CI tem como principal papel nesse processo de construção da identidade do povo, e consequentemente a evocação da memória, fornecer a possibilidade de acesso aos estoques informacionais necessários para o resgate da memória. Os profissionais da informação devem estar aptos, com habilidades e competências para promover esse acesso, sobretudo quando se tratar de comportamentos apropriados e exigidos para a formação do conteúdo.

\section{REFERÊNCIAS}

BERGSON, Henri. Matéria e memória: ensaios sobre a relação do corpo com o espírito. 2. ed. São Paulo: Martins Fontes, 1999.

CANDAU, Joël. Memória e identidade. São Paulo: Contexto, 2011.

DODEBEI, Vera Lucia Doyle Louzada de Mattos. Informação, memória, conhecimento: convergência de campos conceituais. In: ENCONTRO NACIONAL DE PESQUISA EM CIÊNCIA DA INFORMAÇÃO, 11., 2010, Rio de Janeiro. Anais... Rio de Janeiro: ANCIB, 2010.

HALBWACHS, Maurice. A memória coletiva. São Paulo: Centauro, 2006.

NORA, Pierre. Entre memória e história: a problemática dos lugares. Revista do Programa de Estudos Pós-Graduados em História e do Departamento de História, São Paulo, n. 10, 1993. 
OLIVEIRA, Eliane Braga de; RODRIGUES, Georgete Medleg. As concepções de memória na Ciência da Informação no Brasil: estudo preliminar sobre a ocorrência do tema na produção científica. In: ENCONTRO NACIONAL DE PESQUISA EM CIÊNCIA DA INFORMAÇÃO, 9., 2008, São Paulo. Anais... São Paulo: USP/ANCIB, 2008.

;___. O conceito de memória na Ciência da Informação: análise das teses e dissertações dos programas de pós-graduação no Brasil. Liinc em Revista, Rio de Janeiro, v. 7, n. 1, p. 311-328, mar. 2011.

ORRICO, Evelyn Goyannes Dill. O papel da informação na construção da memória coletiva pelo discurso da informação científica. In: ENCONTRO NACIONAL DE PESQUISA EM CIÊNCIA DA INFORMAÇÃO, 11., 2010, Rio de Janeiro. Anais... Rio de Janeiro: ANCIB, 2010.

PIERUCCINI, Ivete; PERROTTI, Edmir. Memória experiência e informação: a estação memória. In: ENCONTRO NACIONAL DE PESQUISA EM CIÊNCIA DA INFORMAÇÃO, 11. 2010, Rio de Janeiro. Anais... Rio de Janeiro: ANCIB, 2010.

PINHEIRO FILHO, Fernando. A noção de representação em Durkheim. Lua Nova, São Paulo, n. 61, 2004.

POLLAK, Michel. Identidade e memória social. Estudos Históricos, Rio de Janeiro, v. 5, n. $10,1992$. $\overline{1989}$.

. Memória, esquecimento, silêncio. Estudos Históricos, Rio de Janeiro, v. 2, n. 3,

RICOEUR, Paul. A memória, a história, o esquecimento. Campinas: Editora da Unicamp, 2007.

SARACEVIC, T. Ciência da Informação: origem, evolução e relações. Perspectivas em Ciência da Informação, Belo Horizonte, v. 1, n. 1, p. 41-62, jan./jun. 1996. 
130 Melo Filho| Identidade e memória na perspectiva da CI

\section{SOBRE O AUTOR}

\section{Edilson Targino Melo Filho}

Doutorando em Ciência da Informação pela Universidade Federal do Rio de Janeiro em parceria com o Instituto Brasileiro de Informação, Ciência e Tecnologia. Mestre em Ciência da Informação pela Universidade Federal da Paraíba. Bibliotecário-Documentalista do Instituto Federal de Educação, Ciência e Tecnologia de Pernambuco.

E-mail: edilsondmelo@gmail.com

Recebido em: 05/09/2016; Aceito em: 18/11/2016.

\section{Como citar este artigo}

MELO FILHO, Edilson Targino. Relações teórico-conceituais entre identidade e memória na perspectiva da Ciência da Informação. Informação em Pauta, Fortaleza, v. 1, n. 2, p. 116-130, jul./dez. 2016. 